\title{
BMJ Open Respiratory syncytial virus: a systematic scientometric analysis of the global publication output and the gender distribution of publishing authors
}

\author{
Dörthe Brüggmann, ${ }^{1,2}$ Corinna Köster, ${ }^{2}$ Doris Klingelhöfer, ${ }^{2}$ Jan Bauer, ${ }^{2}$ \\ Daniela Ohlendorf, ${ }^{2}$ Matthias Bundschuh,, ${ }^{2}$ David A Groneberg ${ }^{2}$
}

To cite: Brüggmann D, Köster C, Klingelhöfer D, et al. Respiratory syncytial virus: a systematic scientometric analysis of the global publication output and the gender distribution of publishing authors. BMJ Open 2017;7:e013615. doi:10.1136/ bmjopen-2016-013615

Received 25 July 2016 Revised 1 March 2017 Accepted 8 March 2017

\section{CrossMark}

${ }^{1}$ Department of Obstetrics and Gynecology, Keck School of Medicine of USC, Los Angeles, California, USA

${ }^{2}$ Institute of Occupational Medicine, Social Medicine and Environmental Medicine, Goethe University Frankfurt, Frankfurt, Germany

Correspondence to Dr Dörthe Brüggmann; doerthe.brueggmann@med. usc.edu

\section{ABSTRACT}

Objective Worldwide, the respiratory syncytial virus (RSV) represents the predominant viral agent causing bronchiolitis and pneumonia in children. To conduct research and tackle existing healthcare disparities, RSVrelated research activities around the globe need to be described. Hence, we assessed the associated scientific output (represented by research articles) by geographical, chronological and socioeconomic criteria and analysed the authors publishing in the field by gender. Also, the 15 most cited articles and the most prolific journals were identified for RSV research.

Design Retrospective, descriptive study.

Setting The NewQIS (New Quality and Quantity Indices in Science) platform was employed to identify RSVrelated articles published in the Web of Science until 2013. We performed a numerical analysis of all articles, and examined citation-based aspects (eg, citation rates); results were visualised by density equalising mapping tools.

Results We identified 4600 RSV-related articles. The USA led the field; US-American authors published 2139 articles (46.5\%\% of all identified articles), which have been cited 83000 times. When output was related to socioeconomic benchmarks such as gross domestic product or Research and Development expenditures, Guinea-Bissau, The Gambia and Chile were ranked in leading positions. A total of 614 articles on RSV (13.34\% of all articles) were attributed to scientific collaborations. These were primarily established between high-income countries. The gender analysis indicated that male scientists dominated in all countries except Brazil.

Conclusions The majority of RSV-related research articles originated from high-income countries whereas developing nations showed only minimal publication productivity and were barely part of any collaborative networks. Hence, research capacity in these nations should be increased in order to assist in addressing inequities in resource allocation and the clinical burden of RSV in these countries.

\section{INTRODUCTION}

The human respiratory syncytial virus (RSV) is the predominant viral agent affecting the respiratory tract worldwide. ${ }^{12}$ It is
Strengths and limitations of this study

- This is the first concise depiction of the worldwide scientific productivity related to respiratory syncytial virus, which was assessed by geographical, chronological and socioeconomic criteria.

- The NewQIS (New Quality and Quantity Indices in Science) platform combines scientometric methods and 'density equalizing mapping projections' to evaluate the scientific output regarding quantitative and qualitative aspects, geographical and chronological developments, existing research networks and socioeconomic benchmarks in a reliable and standardised way.

- Since the Web of Science has a preference for English journals, we have to acknowledge a language bias associated with our analysis.

- Citation-based parameters were assessed, which have limitations since these rather reflect the recognition of the research in the scientific community than truly measure quality.

associated with 64 million infections that occur primarily in children under 5 years. ${ }^{3}$ RSV belongs to the Paramyxoviridae family and is a negative-sense, non-segmented, single-stranded RNA virus, which is mostly transmitted by droplets. ${ }^{4}$ RSV causes bronchiolitis, pneumonia, bronchitis and croup. It is linked to recurrent wheezing and paediatric asthma. ${ }^{56}$ There is no definitive treatment for RSV-related conditions. Although the development of effective and safe vaccines has remained unsuccessful to date, the variety of candidate vaccines is constantly growing in the last years. ${ }^{7}$ One prophylactic agent is commercially available, the neutralising anti-RSV antibody palivizumab. Its use is limited to preterm babies, chronic lung disease of prematurity and infants with congenital heart disease. ${ }^{8}$

RSV-associated morbidity and mortality depends on many factors such as the 
geographic location, climate patterns, genetic susceptibility, socioeconomic factors and local virus strains. ${ }^{3}$ The percentage of children having contracted RSV by their second year of life approaches $100 \% .{ }^{910}$ In the USA, over 2 million children aged 5 years and below need medical attention to treat their RSV infection every year. ${ }^{11}$ On average, $0.3 \%$ of these children and $0.7 \%$ of infants younger than 6 months require hospitalisation. ${ }^{11}$ The general RSV mortality rate in this demographic varies between $0 \%$ and $33 \% .{ }^{10}$ Worldwide, up to 199000 children die due to RSV infections. Ninety-nine per cent of these deaths occur in in developing countries, ${ }^{3}$ hence RSV represents a substantial burden for community health in these nations. According to WHO field studies in 10 developing countries, RSV causes $70 \%$ of all acute respiratory tract infections in children below 5 years of age. ${ }^{12}$ Here, the virus is identified in about $15 \%-40 \%$ of the hospitalised children with pneumonia or bronchiolitis. ${ }^{13}$ RSV epidemics occur during rainy seasons in tropical climates and during the winter months in temperate zones. ${ }^{4}$ Both virus strains, RSV-A and RSV-B, cocirculate during respective outbreaks. The A subtype is typically associated with more severe disease ${ }^{14}$ Distinct genotypes of both strains (identified by the genetic classification of their $G$ protein) are predominant in any given year. This pattern is highly flexible, varies by region and may shift to other prominent genotypes the following year. ${ }^{15}$ Epidemiological studies are dedicated to characterise the distribution of RSV strains and genotypes worldwide, often leading to the identification of new variants such as the RSV Thailand B strain . ${ }^{16}$

Although care of patients with RSV has been improved considerably and extensive studies have been launched to estimate viral spread and disease burden in developing countries, tremendous challenges still remain. In regard to the high prevalence, morbidity and mortality of RSV worldwide, we consider that further research and the implementation of related public health measures are crucial for future successes. However, global research funds are limited and their allocation becomes challenging. In this context, the assessment of the scientific performance is a prerequisite for the reasonable distribution of monetary support and the planning of future research endeavours by scientists interested in the field. Hence, we employed scientometric tools with the goals (1) to determine the RSV-related publication output among the extensive amount of biomedical publications and (2) to evaluate the scientific productivity of single countries in the framework of the global research landscape and in relation to socioeconomic and gender aspects. We also identified the 15 most cited landmark articles and the most prolific journals in the field of RSV research.

\section{METHODS}

\section{Methodical platform}

We used the NewQIS (New Quality and Quantity Indices in Science) platform to assess the worldwide RSV publication activity in a reliable and standardised way. This tool combines scientometric methods and 'density equalizing mapping projections' (DEMP) ${ }^{17-19}$ to evaluate the publication output regarding quantitative and qualitative aspects, geographical and chronological developments, existing research networks and socioeconomic benchmarks.

\section{Density equalising mapping}

DEMP is a state-of-the-art technique to visualise benchmarking processes by anamorphic maps. ${ }^{17}{ }^{20}$ Based on the algorithm of Gastner and Newman, the size of each country was modified analogously to country-specific data on RSV research leading to a new geographic distribution of the global landscape. ${ }^{17}$

\section{Data collection}

For data collection, the Web of Science (WoS) Core Collection database (Thomson Reuters) was employed. The following search term was created: Title $=($ 'RSV' OR 'Respiratory Syncytial Virus' OR 'RS Virus*') NOT Topic=(Rous Sarcoma). The Boolean operator NOT was used to exclude all publications concerning the Rous sarcoma (virus). We limited our search to original research articles. Following our protocol, the time frame was restricted from 1900 to 2013; publications in 2014 were not regarded due to incomplete data acquisition at the time the study was performed.

\section{Data analysis}

RSV-related articles were analysed regarding quantitative aspects such as the total number of publications, citation numbers, countries of article origin (defined as the "country where the institution is located each author, who worked on publishing the article, is affiliated'), institutions, languages, cited reference numbers and publication date. The number of authors publishing on RSV was only quantified for the years with 30 or more annual publications. Also, h-Indices, and the average citation number per item (citation rate, CR) were investigated. Regression analysis was used to investigate the chronological evolution of RSV research. We calculated the coefficient of determination $\left(\mathrm{r}^{2}\right)$ representing the slope of the growth in scientific output and citations.

\section{Modified Hirsch-Index}

The Hirsch-Index (h-Index) is a recognised semiqualitative proxy measure to assess the impact of one author's research output on the scientific community. ${ }^{21}{ }^{22}$ An h-Index of 12 indicates that out of 12 published papers each has been cited at least 12 times. In this study, we applied this concept to the RSV-specific research productivity of single countries and calculated a 'modified country-specific' h-Index. 


\section{Country-specific gender analysis}

The proportionality of male and female researchers among authors publishing on RSV was analysed. Online name databases were used to identify the authors' genders. ${ }^{23}$ If first names were not gender specific or quoted as initials, a manual search (using websites, corresponding addresses and social networks) was launched. We only evaluated countries where a minimum of 60 authors were affiliated and a minimum of $50 \%$ of authors were identified by gender to ensure a valid analysis. These thresholds were chosen arbitrarily based on previous studies.

\section{Cooperation analysis}

We identified all RSV-associated publications that were issued due to international collaborative efforts. The total count of collaborative items was related to the overall number of publications for each investigated country. In brief, if at least two authors originating from different institutions or countries (as identified by the affiliations in the article) contributed to one article, this publication was defined as a collaborative item. Publications with two or more authors affiliated to the same country were counted one time only towards the complete count of joint publications of this particular country. If an author had two affiliations, these were counted for every country mentioned in the affiliations. Connecting vectors visualised these cooperations; their width and shade of grey reflected the number of joint publications.

\section{Journal analysis}

The journals publishing on RSV were analysed regarding quantitative and qualitative aspects, for example, number of published RSV articles as well as citations these items received (citation rate, $\mathrm{CR}$ ).

\section{Analysis of economic key figures}

Two quotients were calculated to assess the scientific output of a specific country: (1) in relation to the number of inhabitants (Q1); and (2) in relation to its economic power (as measured by the gross domestic product, GDP, Q2). Data regarding the population and GDP of investigated countries were obtained from 2012 from the CIA World Factbook. ${ }^{24}$ We computed the quotients in the following way:

1. Articles/population index $(\mathrm{Q} 1)=$ number of articles/ population in millions

2. Articles/GDP index $(\mathrm{Q} 2)=$ number of articles/GDP in billions

All countries were classified into high-income, upper-middle-income, lower-middle-income and low-income groups according to World Bank definitions. ${ }^{25}$

We compared the total number of RSV articles to the gross domestic expenditure on Research and Development (R\&D; in \% of GDP) as well as to the number of researchers (per billion inhabitants) affiliated to the investigated countries. ${ }^{26}$ The analysis was limited to

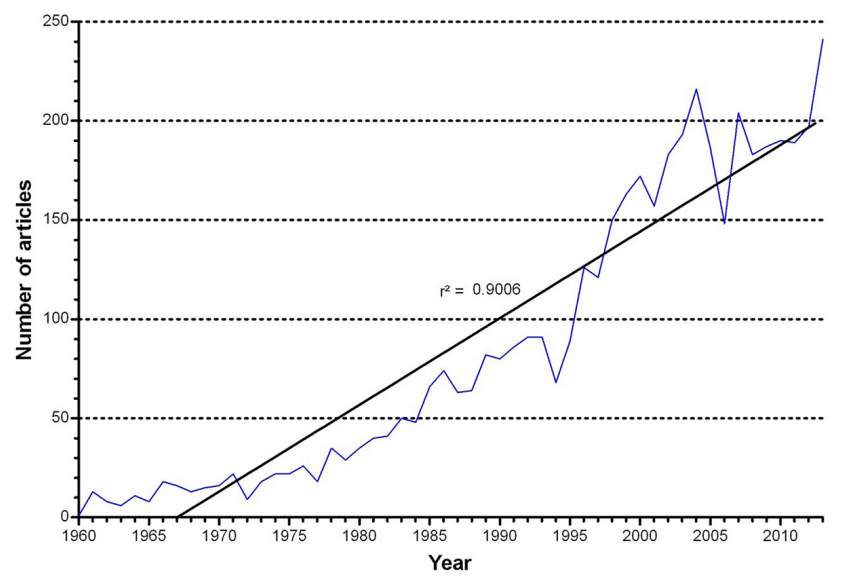

Figure 1 Chronological development of the number of articles.

countries that published a minimum of 30 articles in the field of RSV.

\section{RESULTS}

\section{Number of published items}

We identified 4600 articles on RSV published between 1900 and 2013; $2645(57.5 \%)$ of these were issued after 2000. 1960 and onwards, the number of articles increased significantly over time as indicated by $\mathrm{r}^{2}=0.9$ (figure 1 ). A total of 10791 authors published in the field of RSV. The number of authors per article increased by $100 \%$ in the investigated time frame. We identified a mean of 3.8 and a median of 3 authors in 1978, which was the first year with more than 30 annual publications. Ten years later, a mean of 4.59 and a median of 4 authors were found, followed by a mean of 5.05 and a median of 5 authors in 2000, a mean of 5.95 and a median of 5 authors in 2006, and a mean of 7.6 and a median of 6 authors in 2013 .

\section{Analysis of research origin and citations}

Although the publications originated from 92 of the 251 investigated countries and autonomous regions, the majority of the articles were written in English (4444 articles, $96.6 \%$ of all published RSV articles), followed by French ( 64 articles, $1.4 \%$ of all articles) and German (32 articles, $0.7 \%$ of all articles). More than $85 \%$ of the global publication output was issued by authors from high-income economies. The USA was the most productive nation (2139 articles, $46.5 \%$ of all published RSV articles), followed by the UK (583 articles, $12.7 \%$ ), the Netherlands (231 articles, 5.0\%), Canada (217 articles, $4.7 \%$ ) and Germany (196 articles, $4.3 \%$ ). Hence, the USA and UK dominated the cartogram, while major parts of Africa (with the exception of South Africa), Asia (with the exception of Japan, China, South Korea and India) and Central America occupied only minor areas (figure 2A).

The country-specific citation numbers and modified h-Indices showed a global distribution similar to the number of publications. Articles with US-American affiliation of the authors were cited most (83000 citations, c), 

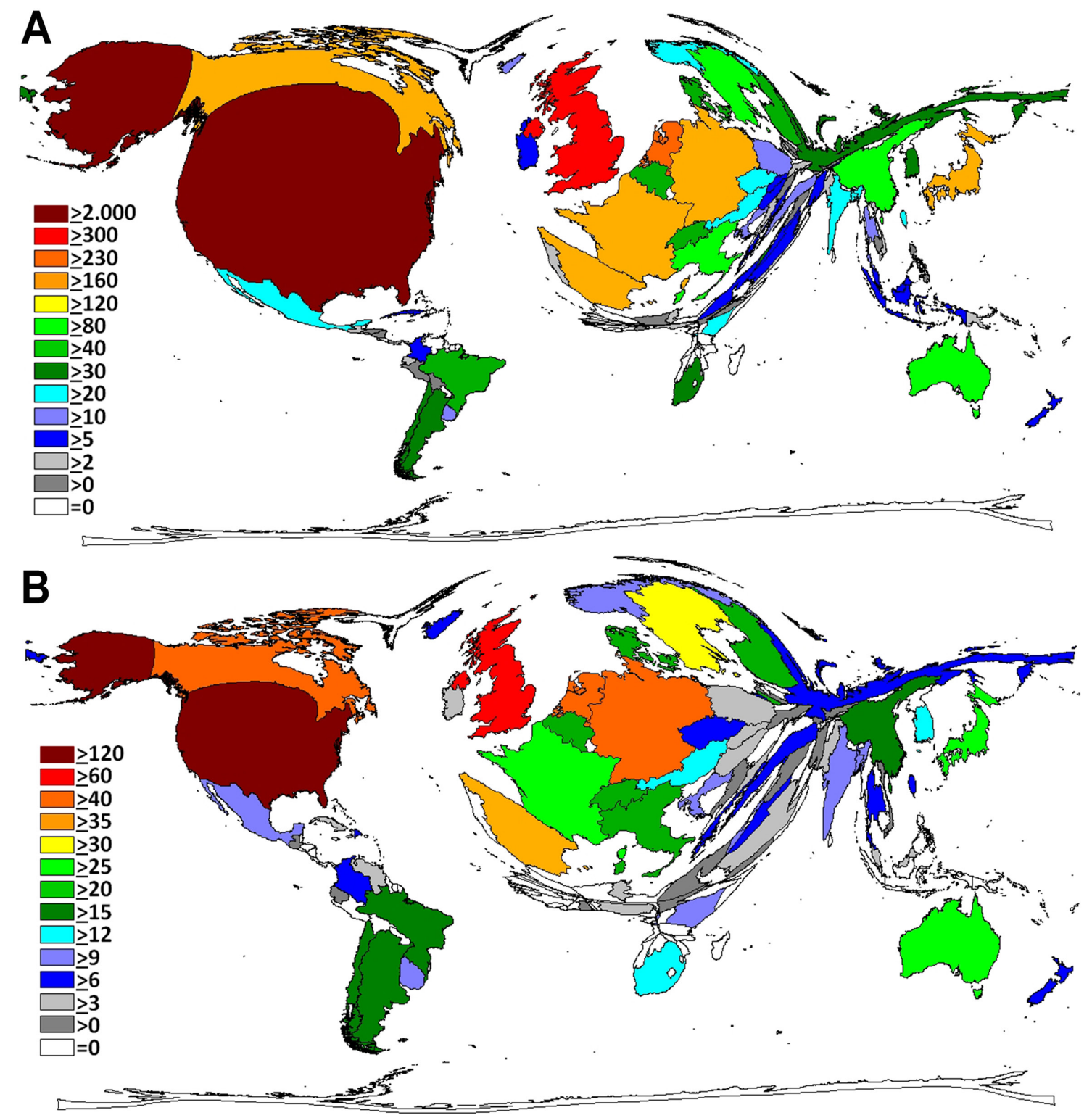

Figure 2 Density equalising mapping projections. (A) Number of publications. (B) Modified h-Index.

followed by articles from the UK ( $c=19240)$, the Netherlands (c=5587), Canada (c=5549) and Germany (c=5319). Articles published by African, Asian and Middle American authors received hardly any citations.

The USA and the UK were the top-ranked countries with a modified h-Index of 121 (USA) and 68 (UK), followed by the Netherlands (h-Index $=44)$, Germany (h-Index $=43$ ) and Canada (h-Index=40) (figure 2B).

Regarding the country-specific CR (average number of citations per total number of publications for each country with more than 30 articles, CR), Sweden $(C R=40)$ dominated and was followed by the USA $(\mathrm{CR}=38.8)$, Finland $(C R=34.9)$, the UK and Germany $(C R=27.13)$.

\section{Analysis of citation performance}

The absolute citation count of all identified RSV-related articles resembled the growing volume of published papers in the investigated time frame. We documented a significant positive correlation between citation numbers and the time of publication (with $\mathrm{r}^{2}=0.72$ for the time frame from 1960 to 2008). The annual citation counts grew from 1960 to 1994 (eg, from 19 annual citations in 1960 to 2448 annual citations in 1994); after 1995, a rapid increase followed until 2003 (eg, 5274 annual citations in 1997 and 7790 annual citations in 2003) whereas a steep decline was noticed after 2006 (eg, 3147 annual citations in 2006). We identified visible peaks in citation activity for 1969 (2294 annual citations), 1986 (3898 annual citations), 2000 (7411 annual citations) and 2003 (7790 annual citations) (figure 3). Additionally, we compiled the 15 most-cited RSV articles, which constitute the publications that have sparked the most documented interest in the field to date (table 1).

\section{Relation to economic parameters}

Relating the number of publications to the population of a country, high-income countries such as Iceland $(\mathrm{Q} 1=34.59)$, the Netherlands $(\mathrm{Q} 1=13.90)$ and Denmark 


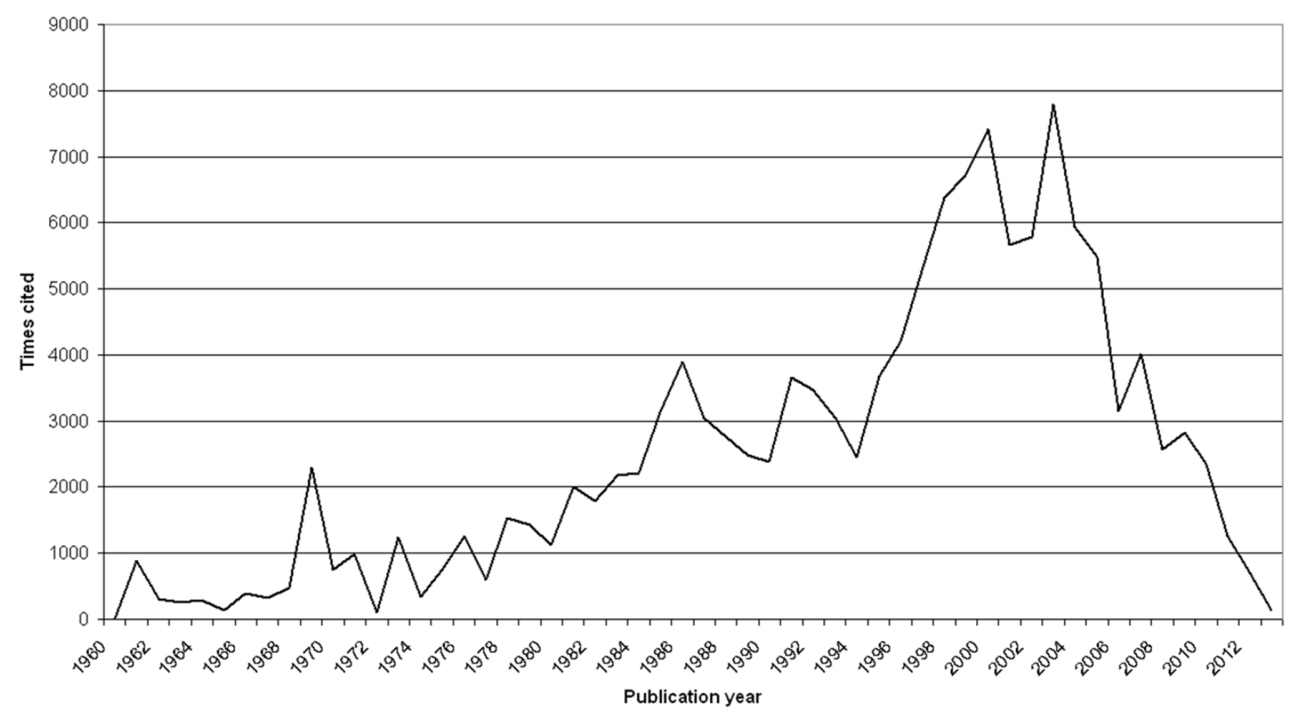

Figure 3 Chronological development of annual citation numbers.

$(\mathrm{Q} 1=12.25)$ issued a higher number of publications per million inhabitants compared with low-income or lower-middle-income countries, for example, Nigeria $(\mathrm{Q} 1=0.03)$ and Indonesia $(\mathrm{Q} 1=0.02)$ (figure 4A). We identified two exceptions, which included the low-income countries Guinea-Bissau $(\mathrm{Q} 1=6.30)$ and The Gambia $(\mathrm{Q} 1=4.76)$. Both were represented among the 15 top-ranked countries in this analysis.

When looking at the publication activity in relation to GDP, two low-income countries outperformed high-income nations (figure 4B). Guinea-Bissau (Q2=11.776) and The Gambia $(\mathrm{Q} 2=8.721)$ again held leading positions, followed by Iceland $(\mathrm{Q} 2=0.810)$, Kenya $(\mathrm{Q} 2=0.516)$ and Croatia $(\mathrm{Q} 2=0.319)$. Besides these two exceptions, other low-income or lower-middle-income countries showed a weak performance (eg, Philippines with Q2=0.004 or Indonesia with $Q_{2}^{2}=0.007$ ). Also, the USA did not remain under the top 10 nations and was found at position 18 (Q2=0.132).

Chile, the Netherlands, South Africa, UK and Argentina were leading the analysis when the total article count was related to the country-specific R\&D expenditures (33.72, 13.32, 12.14, 11.46 and 9.56 articles per billion GDP spent on R\&D, respectively). The USA dropped to position 11 with 4.52 articles per billion GDP spent on R\&D (figure 5A, table 2).

When we related the article count to the number of researchers (per billion inhabitants) as a proxy measure for the active research community working on RSV and the productivity of these researchers, the USA was leading the field (532.27 articles per researcher per billion inhabitants), followed by the UK, China, Chile and South Africa (137.10, 83.55, 77.10 and 76.60 articles per number of researchers per billion inhabitants) (figure 5B, table 3 ).

\section{Country-specific gender analysis}

We identified the gender distribution among authors working on RSV in institutions affiliated to 92 countries. Our analysis indicated a larger proportion of male scientists in almost all evaluated countries (figure 6). Brazil was an exception. Ninety-five authors with affiliation to Brazilian institutions were identified as working on RSV. Sixty-two of those were identifiable by name and gender. Here, men and women were almost equally represented (32 female authors, $51.6 \%$ of identifiable authors, 30 male authors, $48.4 \%$ of identifiable authors). By calculating the proportion of male to female scientists $(\mathrm{m} / \mathrm{f}$ ratio), we documented the lowest ratio $(\mathrm{m} / \mathrm{f}$ ratio $=0.94)$ for Brazil, followed by Germany $(\mathrm{m} / \mathrm{f}$ ratio=1.1). Japan had the highest score with $\mathrm{m} / \mathrm{f}$ ratio $=2.8$.

\section{International cooperation analysis}

The first collaborative article on RSV was identified in 1973. It was published by researchers working in institutions located in Switzerland and the USA. ${ }^{27}$ Since 1973, a total of 614 joint articles were published on RSV accounting for $13.34 \%$ of all articles. The USA was the preferred partner for international collaborations on RSV. The most productive cooperation was established between the USA and the UK (67 joint works, $10.9 \%$ of collaborative articles), followed by the USA and Canada (45 joint articles, $7.3 \%$ of collaborative articles), and the USA and Germany (34 joint articles, $5.5 \%$ of collaborative articles).

The most fruitful cooperation not involving the USA existed between the UK and Spain (33 joint articles, 5.4\% of collaborative articles). The most productive cooperation between high-income and lower-middle-income or low-income economies was set up between Kenya and the UK (18 joint articles, 2.9\% of collaborative articles), followed by Guinea-Bissau and Denmark (10 joint articles, $1.6 \%$ of collaborative articles). Overall, cooperations with low-income or lower-middle-income countries were less popular (figure 7).

\section{Journal analysis}

When we identified the most prolific journals in RSV research, the 'Journal of Virology' led the field (334 


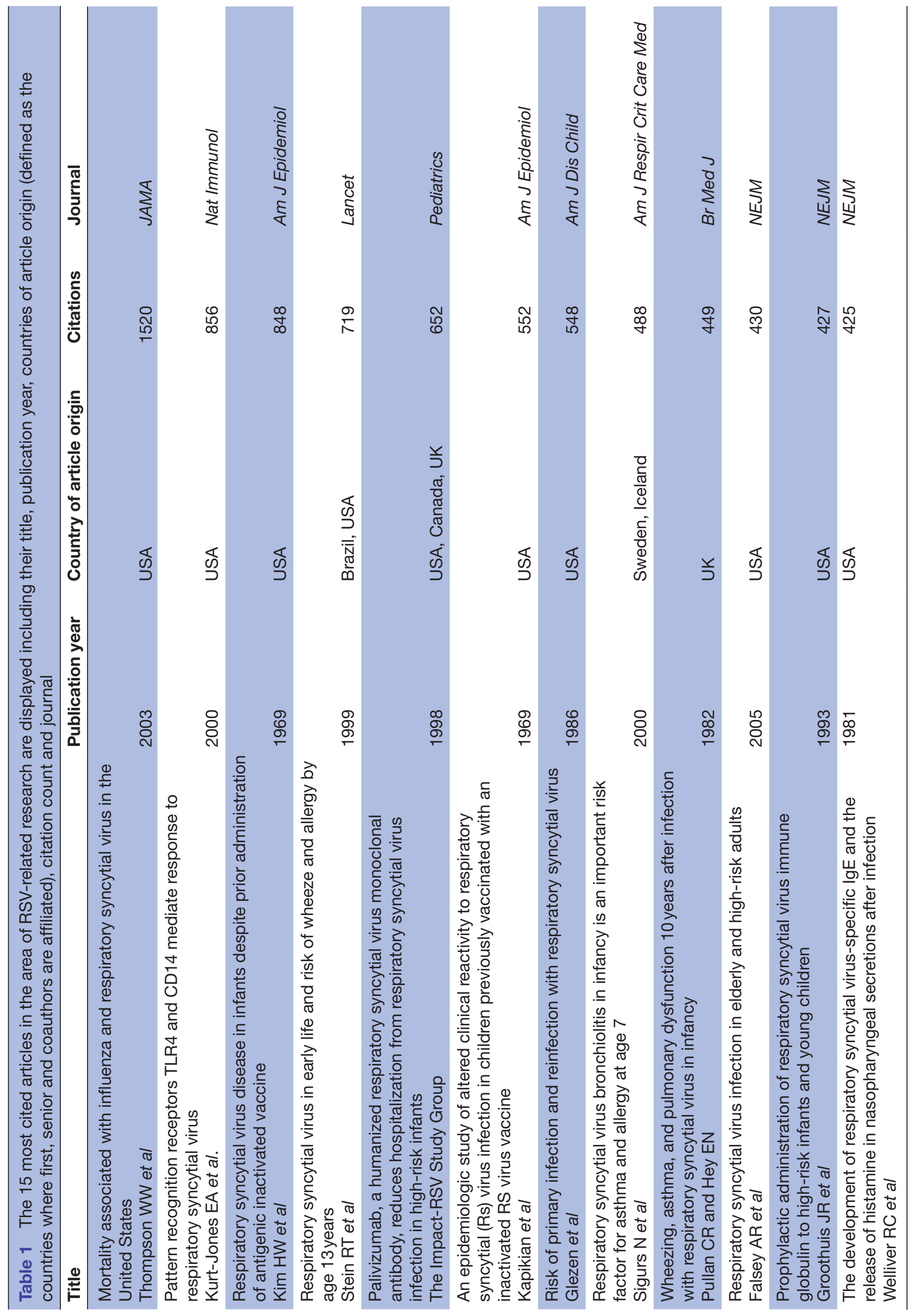




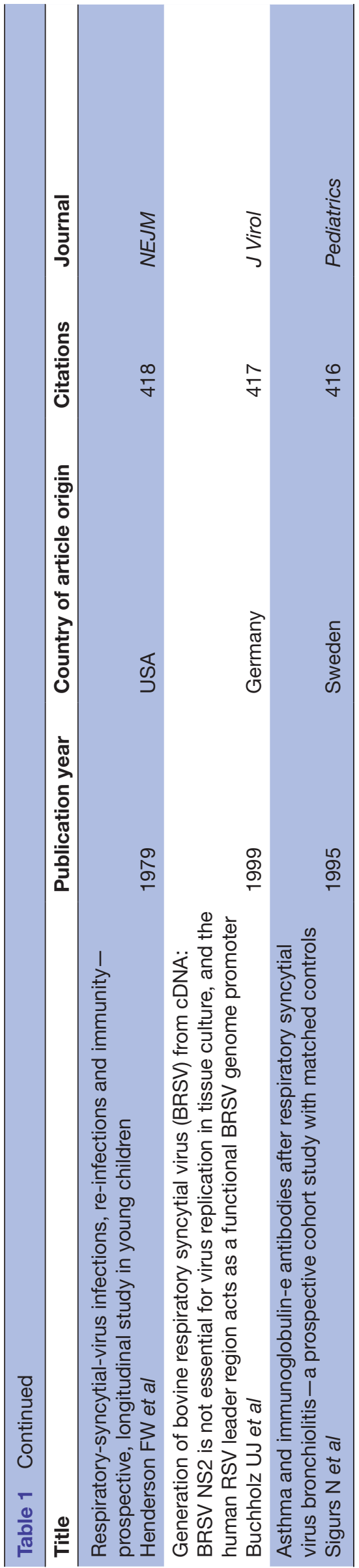

articles, CR of 45.49), followed by 'The Pediatric Infectious Disease Journal' (198 articles, $\mathrm{CR}=24.66$ ) and the 'Journal of Infectious Diseases' (186 articles, CR 55.18) (figure 8). The highest CR was achieved by the 'Proceedings of the National Academy of Sciences of the United States of America' (42 articles, CR=81.43), followed by 'Pediatrics' ( 66 articles, CR=70.80), 'Journal of Pediatrics' (65 articles, $\mathrm{CR}=64.03$ ), 'American Journal of Respiratory Critical Care' ( 47 articles, CR=62.55) and 'Journal of Infectious Diseases' (186 articles, $\mathrm{CR}=55.18$ ).

\section{DISCUSSION}

In the WoS, we documented only 4600 RSV-related articles since 1900. The first item on the disease in humans was published in $1957 .^{28}$ This emphasises that research on RSV is a relatively new field considering the virus was initially isolated in 1956 from laboratory primates. ${ }^{29}$ The predominance of English in the majority of identified articles aligns with the fact that this language is the recognised 'scientific lingua franca' and reflects the abundant research output of English-speaking countries such as the USA, Canada and the UK found in our study.

The increasing number of RSV publications over time is typical for most biomedical research, for example, on the John Cunningham virus, influenza or breast cancer. ${ }^{3031}$ Overall, the steady growth of article numbers can be explained by the rising interest in the field due to the increasing relevance of RSV in pneumonia and child mortality. ${ }^{9}$ In the first few years after the detection of the virus, basic research was conducted. These endeavours, which aimed to characterise the virus, identify immunologic responses and develop vaccines, translated into a growing volume of articles on RSV. ${ }^{32-35}$ The continuous increase since the beginning of the 1990s may be attributed to the launch of a growing number of scientific journals providing a platform for publishing. The development of modern communication systems based on new computer technologies such as the World Wide Web made it easier to communicate, exchange ideas and publicise articles in central databases. Also, it is noticeable that the increasing publication output since the 1960s was paralleled by a globally growing funding volume allocated to the R\&D sector. In the USA alone, a total of US $\$ 13711$ million was allocated to R\&D in 1960 as documented by the National Science Foundation. This amount increased to US\$26271 million in 1970 and US $\$ 452556$ million in 2012 (https://www.nsf.gov/statistics/2015/nsf15315/).

The chronological development in publication quantity (figure 1) was resembled by the steady increase of related citations (figure 3). Four prominent citation peaks in 1969, 1986, 2000 and 2003 coincided with milestone papers in the field. In 1969, adverse effects of the formalin-inactivated RSV vaccine in children were reported. ${ }^{36}$ Large epidemiological studies investigated the risks of reinfection and the mortality associated with RSV in 1986 and $2003 .{ }^{37}$ The research on a prophylactic antibody 

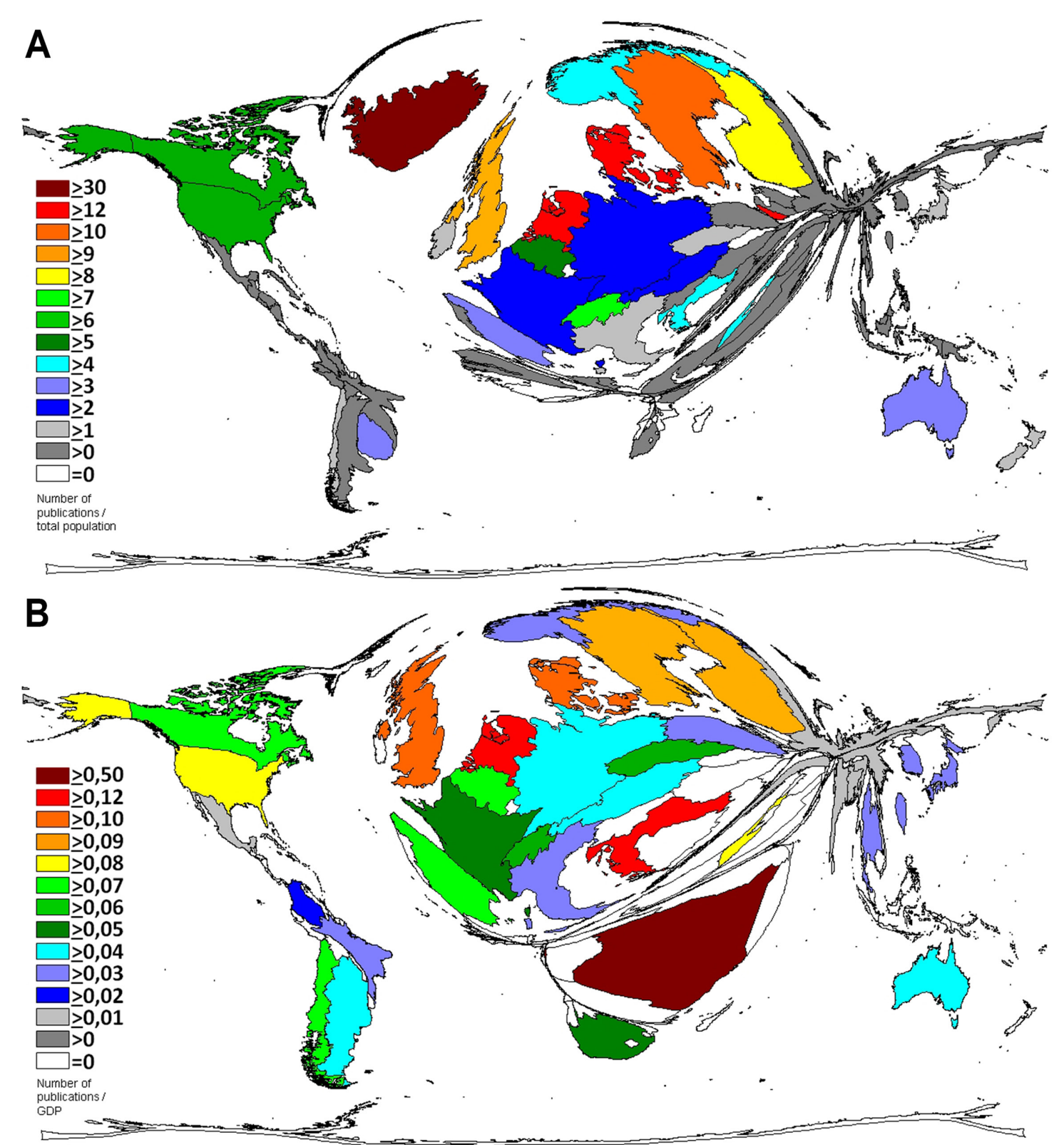

Figure 4 Density equalising mapping projections. (A) Articles/population index (Q1). (B) Articles/GDP index (Q2) (threshold $\geq 15$ articles). GDP, gross domestic product.

licensed in 1999 and novel insights into immunologic responses involving pattern recognition receptors TLR4 and CD14 may be responsible for the peaking number of publications and citations in $2000 .^{39}$ The citation decline after 2006 can be attributed to the short timespan articles had allotted to receive recognition within the scientific community and obtain the appropriate citation number reflecting their true impact. ${ }^{40}$ Hence, we expect this trend to be reversed in the future.

The USA dominated RSV research with regard to overall publication quantity, citation numbers and h-Index. This corresponds with a previous biomedical benchmarking study. Here, the USA was the most productive nation and authored 1893800 of 5527558 publications related to 22 organ systems from 1961 to $2007 .^{41}$ The leading role of the USA might be linked to major financial resources this nation dedicates to research. The US-American National Institutes of Health is by far the biggest biomedical funder in the world (eg, with a funding volume of US $\$ 26.08$ billion in 2013 compared with the biggest funding source in the European Union, the European Commission, with a funding volume of US $\$ 3.71$ billion in 2013). Also, the Department of Defense constitutes another large US-American funding organisation with a volume of US $\$ 1.017$ billion (2013), followed by private philanthropic institutions such as the Howard Hughes Medical Institute or the Bill \& Melinda Gates Foundation with impressive funding volumes of US $\$ 752.0$ million (2013) and US $\$ 462.6$ million (2011), respectively. ${ }^{42}$ These funds can support manpower and an outstanding scientific infrastructure illustrated by the fact that the majority of institutions working on RSV were 

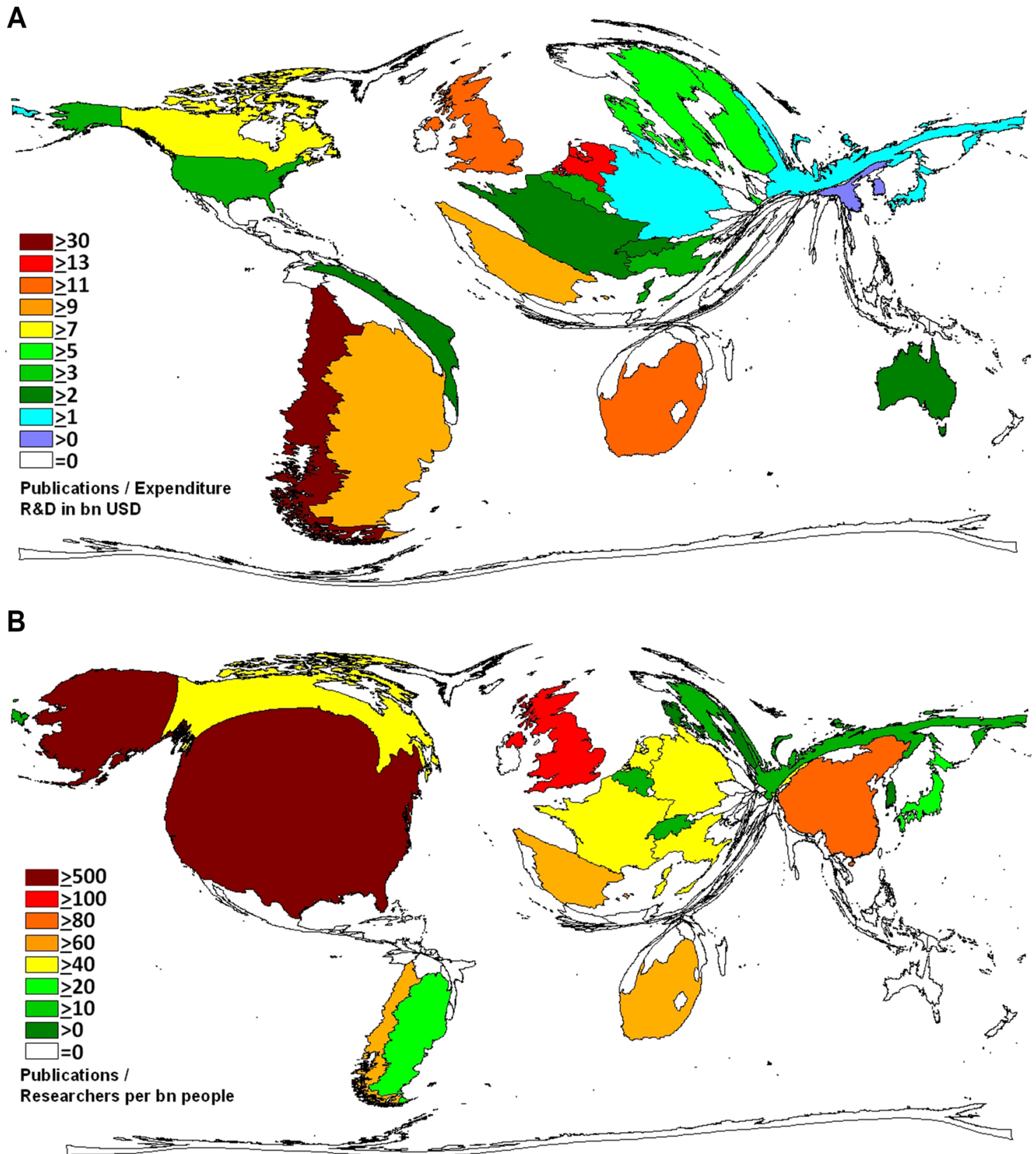

Figure 5 Density equalising mapping projections. (A) Articles/R\&D expenditure in billion USD index. (B) Articles/researcher (per billion inhabitants) index (threshold $\geq 30$ articles). R\&D, Research and Development; USD, US dollars.

identified in the USA, and that this nation is a preferred partner for national and international cooperations.

The cluster of the USA, Western-European countries (eg, UK or Germany) and Japan dominated the overall publication output and analyses of citation-based benchmarks. This finding corresponds with other scientometric studies (eg, on influenza, Ebola or hepatitis B). ${ }^{30} 43$ Although Sweden and Finland published relatively low numbers of articles, they are characterised by the highest CRs in our analysis, indicating the outstanding quality and high recognition their articles received in the scientific community. Furthermore, it was striking that most African, Asian and Central American countries afflicted with a considerable RSV-related burden did not play a visible role in the field. Methodologically, we included only countries in the CR analysis that published more than $30 \mathrm{RSV}$ articles aiming to generate a better validity of the investigation by avoiding overestimation of few but frequently cited articles. Nevertheless, we want to stress that the absolute number of citations as well as the CR should be viewed critically. These parameters can be affected by self-citation and inaccurate citations. Also, the Matthew effect might influence citation-based variables. Here, scientists prefer to cite articles issued by well-known researchers to papers by junior scientists leading to a disproportional increase in the related citation counts. ${ }^{445}$ Hence, we also evaluated the modified h-Index since it is less influenced by outstanding, frequently or rarely cited 
Table 2 Total number of publications related to gross domestic expenditures on Research and Development in billion USD of countries that have published more than 30 items on RSV

\begin{tabular}{clclccc}
\hline Rank & Country & No. of articles & $\begin{array}{l}\text { R\&D } \\
\text { expenditure in } \%\end{array}$ & $\begin{array}{l}\text { GDP in billion } \\
\text { USD }\end{array}$ & $\begin{array}{l}\text { R\&D } \\
\text { expenditure in } \\
\text { billion USD }\end{array}$ & $\begin{array}{l}\text { Articles/billion } \\
\text { USD of R\&D } \\
\text { expenditure }\end{array}$ \\
\hline 1 & Chile & 33 & 0.38 & 258 & 0.98 & 33.72 \\
\hline 2 & Netherlands & 231 & 1.97 & 879 & 17.34 & 13.32 \\
\hline 3 & South Africa & 31 & 0.73 & 349 & 2.55 & 12.14 \\
\hline 4 & UK & 583 & 1.70 & 2990 & 50.85 & 11.46 \\
\hline 5 & Argentina & 31 & 0.61 & 529 & 3.24 & 9.56 \\
\hline 6 & Spain & 160 & 1.23 & 1381 & 17.01 & 9.41 \\
\hline 7 & Canada & 217 & 1.61 & 1783 & 28.73 & 7.55 \\
\hline 8 & Denmark & 68 & 3.08 & 346 & 10.67 & 6.37 \\
\hline 9 & Sweden & 99 & 3.16 & 571 & 18.05 & 5.49 \\
\hline 10 & Finland & 46 & 3,17 & 272 & 8.63 & 5.33 \\
\hline 11 & USA & 2139 & 2.73 & 17348 & 472.78 & 4.52 \\
\hline 12 & Belgium & 56 & 2.46 & 531 & 13.09 & 4.28 \\
\hline 13 & Italy & 84 & 1.29 & 2138 & 27.52 & 3.05 \\
\hline 14 & Switzerland & 62 & 2.97 & 701 & 20.80 & 2.98 \\
\hline 15 & France & 189 & 2.26 & 2829 & 63.82 & 2.96 \\
\hline 16 & Australia & 86 & 2.20 & 1454 & 31.93 & 2.69 \\
\hline 17 & Israel & 33 & 4.11 & 305 & 12.53 & 2.63 \\
\hline 18 & Brazil & 75 & 1.24 & 2417 & 29.87 & 2.51 \\
\hline 19 & Germany & 196 & 2.87 & 3868 & 110.96 & 1.77 \\
\hline 20 & Russia & 37 & 1.19 & 2030 & 24.09 & 1.54 \\
\hline 21 & Japan & 192 & 3.58 & 4596 & 164.73 & 1.17 \\
\hline 22 & South Korea & 36 & 4.29 & 1411 & 60.55 & 0.59 \\
\hline 23 & China* & 93 & 2.05 & 10351 & 211.79 & 0.44 \\
\hline
\end{tabular}

GDP, gross domestic product; RSV, respiratory syncytial virus; R\&D, Research and Development; USD, US dollars. ${ }^{*}$ China without Taiwan.

articles skewing the CR value. ${ }^{21}{ }^{22}$ Furthermore, all citation-based variables have limitations in assessing the quality of the identified articles because they rather reflect the recognition of the research in the scientific community than measure quality.

We identified an over-representation of male authors in the majority of evaluated nations. This corresponds to the study of Head et al who documented the preferential funding of male researchers by UK institutions in the area of global infectious disease research. Between 1997 and 2010, funding agencies supported fewer studies of female PIs and awarded less monetary support to research supervised by women. Particularly for RSV, male researchers received five times more funding than female scientists, who spearheaded only half the funded studies compared with their male counterparts in the field. ${ }^{46} \mathrm{In}$ our gender analysis, Brazil was an exception with a majority of women authoring RSV research (figure 6). This result correlates with previous investigations on yellow fever and rotavirus infections ${ }^{47}$ as well as with gender benchmarking studies (eg, conducted by the 'Konrad-Adenauer Foundation' or the 'Organization for Women in Science for the
Developing World'), which suggests that Brazil pioneers in the support and participation of women in science. ${ }^{48}$

Our analysis of RSV publication outputs changed in relation to economic capabilities (figure 4). Two developing, low-income nations, The Gambia and Guinea-Bissau, occupied the leading positions. This finding points towards the fact that both prioritise RSV research and might be connected to existing cooperations with a longstanding shared history between collaborating nations and their focused support of RSV scientific activities. For example, the UK's 'Medical Research Council The Gambia Unit' and the Danish 'Bandim Health Project' encourage medical research in Guinea-Bissau and The Gambia. ${ }^{50}$ Also, research in the field is promoted by single researchers with a strong dedication to conduct research in African sites. Here, Sir Brian Greenwood has spearheaded RSV-related research very successfully for decades while being faculty at the London School of Hygiene and Tropical Medicine as well as the Director of the Medical Research Council in The Gambia. ${ }^{130-58}$

If the RSV article counts were related to R\&D expenditures and number of researchers in specific countries, a 
Table 3 Total number of publications related to articles per researcher (per billion inhabitants) of countries that have published more than 30 items on RSV

\begin{tabular}{clclc}
\hline Rank & Country & Number of RSV articles & $\begin{array}{l}\text { Number of researchers per } \\
\text { billion inhabitants }\end{array}$ & $\begin{array}{l}\text { Articles/researcher (per } \\
\text { billion inhabitants) }\end{array}$ \\
\hline 1 & USA & 2139 & 4.02 & 532.27 \\
2 & UK & 583 & 4.25 & 137.10 \\
3 & China & 93 & 1.11 & 83.55 \\
4 & Chile & 33 & 0.42 & 77.11 \\
5 & South Africa & 31 & 0.40 & 76.60 \\
6 & Spain & 160 & 2.64 & 60.55 \\
\hline 7 & Netherlands & 231 & 4.48 & 51.58 \\
8 & Canada & 217 & 4.52 & 48.02 \\
9 & France & 189 & 4.20 & 44.99 \\
10 & Germany & 196 & 4.38 & 44.74 \\
11 & Italy & 84 & 2.01 & 41.86 \\
12 & Japan & 192 & 5.39 & 35.65 \\
13 & Argentina & 31 & 1.20 & 25.79 \\
14 & Sweden & 99 & 6.87 & 14.41 \\
15 & Switzerland & 62 & 4.48 & 13.83 \\
16 & Belgium & 56 & 4.18 & 13.41 \\
\hline 17 & Russia & 37 & 3.10 & 11.93 \\
18 & Denmark & 68 & 7.20 & 9.45 \\
19 & Finland & 46 & 7.00 & 6.58 \\
20 & South Korea & 36 & 6.90 & 5.22 \\
21 & Israel & 33 & 8.26 & 4.00 \\
\hline
\end{tabular}

RSV, respiratory syncytial virus. ${ }^{*}$ China without Taiwan.

different, more refined picture emerged compared with the assessments based on absolute publication numbers or related to socioeconomic variables. Here, two Latin American countries gained importance, Chile and Argentina. It appears that these nations invest funding very efficiently in RSV research, with Chile ranked first position with 33.72 RSV articles per billion US dollars in R\&D expenditures followed by Argentina in fifth position (9.56 articles

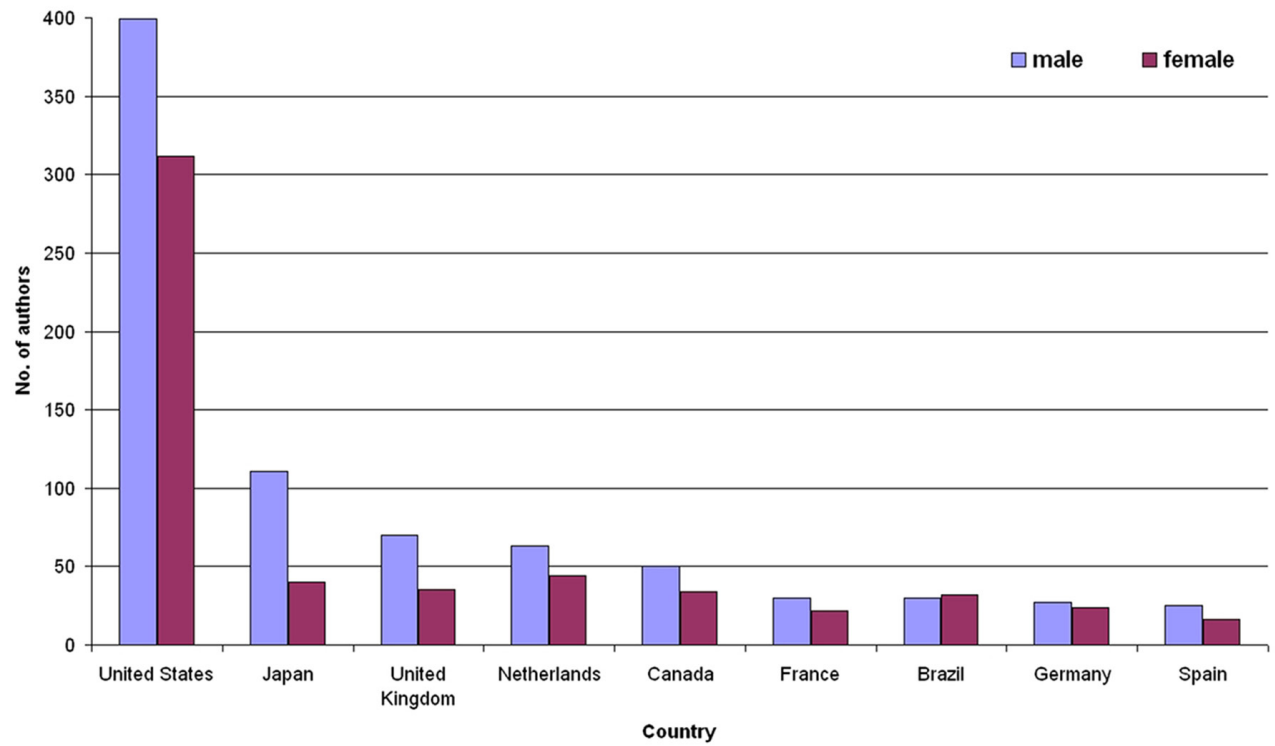

Figure 6 Country-specific gender analysis of the authors publishing articles referring to respiratory syncytial virus of countries (threshold: $>50 \%$ definable genders, $>60$ authors per country). 

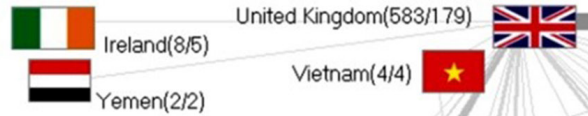

Venezuela(5/4)

Uruguay(12/11)

Tunisia(4/4)

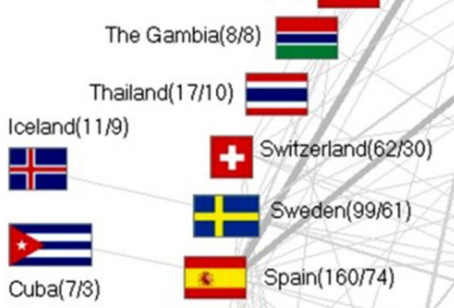

Senegal(2/2)

South Korea(36/6) :0:

Russia(37/6)

South Africa(31/17)

Singapore(14/8)

Norway $(21 / 5)$

Netherlands(231/54)

Mozambique(4/4)

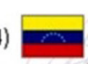



(

(1)
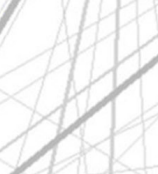

$$
\text { (2) }
$$

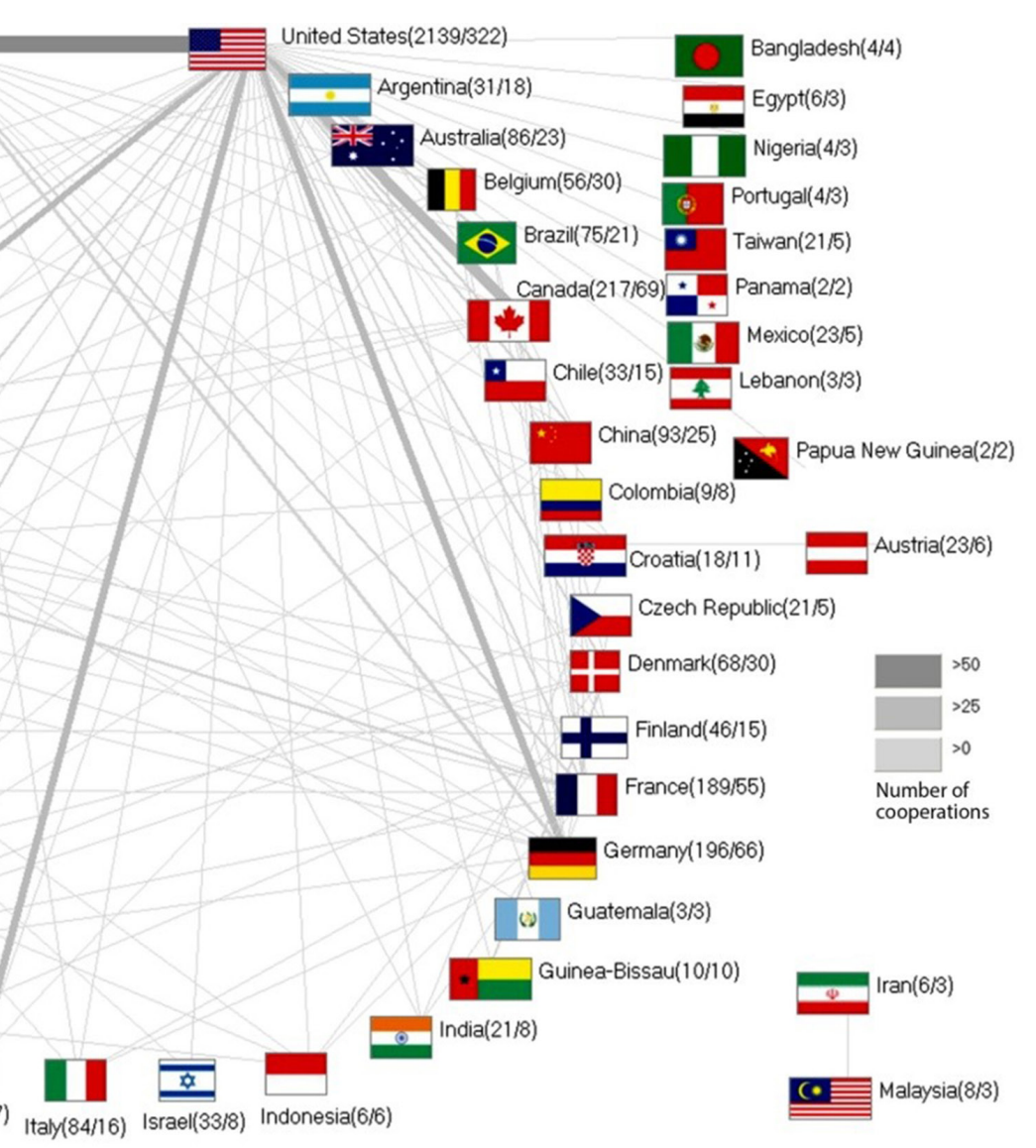

Figure 7 International cooperations on RSV research (threshold $\geq 2$ cooperations). Numbers in brackets report the number of publications in total/collaborative publications .

per billion US dollars in R\&D). Both nations' interest to fund RSV research might be linked to the fact that respiratory infections and RSV in particular impose a heavy burden on the local paediatric population. Respiratory infections constitute the second leading cause of death in Latin American children aged 5 years or below with RSV as the causative agent in $70.0 \%$ of these infections. ${ }^{345960}$ In the temperate climate of Chile and Argentina, RSV causes predictable outbreaks during the summer months. A particular high RSV burden of up to $70 \%$ was reported in Chilean children aged 0-11 months with lower respiratory tract infection. This was substantially higher than

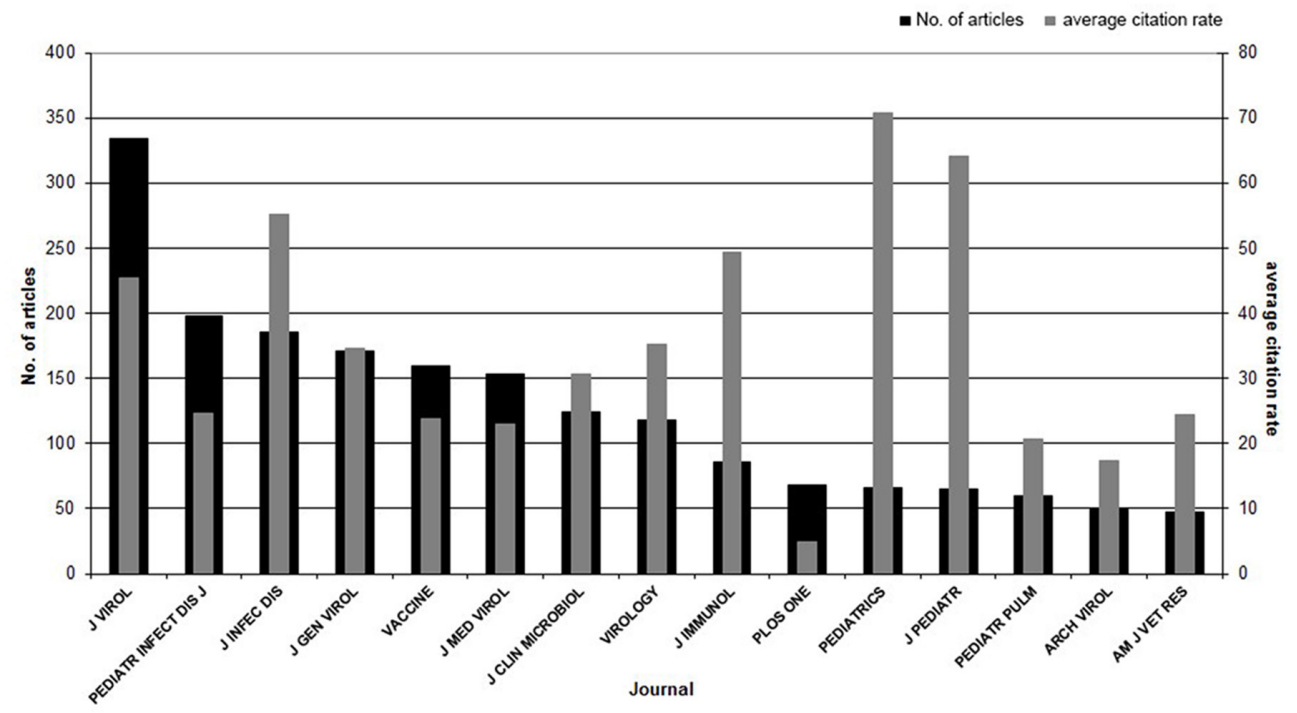

Figure 8 Most prolific journals in the field of respiratory syncytial virus research in regard to overall publication numbers and the average citation rate. 
in other Latin American countries (eg, 18.2\% in Argentina and $44 \%$ in Brazil). ${ }^{61}$ Hence, RSV is constantly in the focus of the local health authorities, which routinely monitor and report the trends in RSV infections to better allocate resources for paediatric patients and limit related morbidity and mortality. ${ }^{61} 62$

Collaborations are becoming increasingly important in the field of RSV research as indicated by existing tightknit networks and the growing numbers of authors per article over time. We link this development to the globalisation process, which connects scientists worldwide to exchange ideas, resources and knowledge facilitated by the growing availability of information technology. Further, it is noticeable that countries such as the USA or European Nations play a more prominent role in international collaborations compared with low-income and lower-middle-income countries. As exceptions, we could identify productive cooperations between the UK and Kenya as well as Denmark and Guinea-Bissau. The relation between Kenya and the UK might be based on their shared history and facilitated by implemented programmes such as the 'KEMRI Welcome Trust Research Program' between the Kenya Medical Research Institute and the University of Oxford. ${ }^{63}$ As revealed by Fitchett et al, ${ }^{64}$ a substantial funding volume goes to infectious disease research in countries with colonial ties to the UK such as Kenya and The Gambia. From 1997 to 2010, these countries received $£ 13.13$ million (The Gambia) and £12.92 million (Kenya) of biomedical funding by UK-based institutions. Research activity on RSV in Guinea-Bissau is also supported by the aforementioned Danish 'Bandim Health Project,' which was founded by the anthropologist Sir Peter Aaby in the 1970s. It gathers local epidemiological data on more than 200000 individuals. Since its foundation, this group has published more than 600 items on vaccines, maternal mortality and childhood infections such as RSV. ${ }^{50}$

Timing, intensity and clinical impact of RSV infections vary worldwide. ${ }^{3}$ Hence, research is still needed to alleviate the burden related to RSV in high-risk populations. Interventions should focus on data collection via established surveillance systems (eg, aiming to define local morbidity and mortality, assist disease modelling and guide prophylactic measures and vaccine development). ${ }^{65}$ In this context, our study revealed a striking discrepancy in scientific productivity and collaborative involvement between high-income and low-income countries. Also, attention should be drawn to a further problem concerning low-income nations or countries whose researchers have a limited financial budget to pay for publication in renowned open access journals. This issue increases the apparent discrepancies regarding publication activities even further. To minimise this problem, a number of waiver programmes currently exist, that is, for journals such as PLOS, Biomed Central or $B M J$ OPEN, ${ }^{66-68}$ but these should be expanded more broadly. However, we can deduce from our findings that developing nations-although experiencing the most significant consequences of RSV epidemics-cannot compete equally in the field of RSV research due to the lack of funding and infrastructure. Therefore, we want to emphasise the need-an almost ethical responsibility-to involve these nations in funding programmes and successful international collaborations as seen for Guinea-Bissau, Kenya and The Gambia. We acknowledge that the establishment of collaborations between high-income and low-income nations is challenging due to the lack of resources, manpower and funding opportunities, the political climate, cultural differences between the potential partners, and an unrealistic assessment of the local research capacity and resources. ${ }^{69}$ Also, existing collaborations and funding streams need to be viewed critically since they should rather reflect local disease burden, apparent healthcare disparities and scientific capability than being allocated based on a shared language or history between countries (eg, guided by former colonial ties). Therefore, funding institutions should revise their policies appropriately. ${ }^{64}$ Also, global investment surveillance systems need to be established such as the 'Research Fairness Initiative' led by Cohred to guide and monitor sustainable, transparent and effective partnerships in research (http://rfi.cohred.org/ origin-of-the-rfi/). Nevertheless, tight-knit networks would be key for developing countries to participate in the international exchange of data, resources and knowledge, and to facilitate their involvement in high-quality research efforts despite an unequal starting point.

\section{Study limitations}

Our study has several limitations. Using the WoS to conduct this analysis is associated with an important strength and with a weakness of the study. The WoS enabled us to assess quantitative and qualitative aspects of the publication output related to RSV research. This is a unique feature allowing a multifaceted evaluation of the publication productivity. On the other hand, the WoS displays a strong preference for English journals. Therefore, not all articles ever published on RSV could be analysed here. However, we regard this bias as limited as the majority of high-quality data are commonly published in international journals indexed by the WoS and therefore definitely included in our search. Also, we acknowledge that not all eligible RSV publications were detected by the conducted 'TITLE' search. This approach was preferred to a 'TOPIC' search, which identifies the search term in the abstract and the keywords leading to a significant amount of off-topic publications compromising the validity of our data collection. We concentrated our study on original articles to focus on published 'cutting edge research' in the field of RSV. We acknowledge that this strategy narrowed down the focus on the topic since other publication types such as commentaries, reviews, case reports or meeting reports were not included. Further, we did not employ any additional platforms such as PubMed, Google Scholar or Scopus to collect bibliometric data because the management, organisation and the scope of data are slightly different among these databases. This 
would affect triangulating, comparing and integrating data related to RSV research in a meaningful way.

We identified the first collaborative article on RSV in 1973, which would indicate that researchers from different countries did not work together on RSV before this point in time. This assumption is not necessarily true. In 1972, the WoS indexed author affiliations for the first time, which indicates that articles published in a joint effort before 1972 would not have been detected by our methodological approach. The evaluation of country-specific publication performance by gender is meaningful but should be evaluated critically. Not all first names were included in our analysis since some were gender neutral, not listed in name databases or displayed as initials. Therefore, the threshold of at least 60 publishing scientists and $50 \%$ gender definability was implemented to include only countries providing meaningful and valid data. Further, we identified 'Mortality associated with influenza and respiratory syncytial virus in the United States' by Thompson et al as the most cited journal article in the field of RSV. It received 1520 citations representing its outstanding recognition in the scientific community. The publication covers the topics RSV as well as influenza, so the limitation has to be mentioned that our computed approach did not differentiate if the article was cited in 'influenza' or 'RSV' papers. Employing a manual analysis, we found that $70.3 \%$ of citing articles can be attributed to influenza, only $15.8 \%$ to RSV, and $2.2 \%$ were covering both topics. Hence, the impact of this particular paper on the field of RSV must be considered as less than it initially appeared based on the citation count alone.

\section{Conclusion}

We evaluated the worldwide RSV-related research output and demonstrated large differences between high-income, middle-income or low-income nations regarding most scientometric variables. These discrepancies partly diminished when country-specific scientific activities were related to economic key measures; here, the leading position of the USA in science was challenged by other nations. Hence, calculating these quotients is beneficial for the comparison of countries with unequal conditions and different scientific infrastructures. However, we can deduce from our study that research efforts of middle-income or low-income nations have to be strengthened, for example, by the reduction of journal fees and inclusion in international collaborations, so apparent disparities can be minimised and higher mortality rates related to RSV in developing nations can be tackled successfully.

Acknowledgements We thank Cristian Scutaru for the development and provision of the NewQIS analysing tools. We also thank Mario Schwarzer, MD, for supporting the study and helpful discussions as well as Jenny M. Jaque, MD, for thoroughly editing our manuscript.

Contributors DB, CK, DK, DAG, DO, JB and MB have made substantial contributions to the conception and design of the study, acquisition of the study data and have been involved in drafting and revising the manuscript. All authors have read and approved the final manuscript.

Funding This research received no specific grant from any funding agency in the public, commercial or not-for-profit sectors.
Competing interests None declared.

Provenance and peer review Not commissioned; externally peer reviewed.

Data sharing statement Datasets of this study are available from the corresponding author upon request.

Open Access This is an Open Access article distributed in accordance with the Creative Commons Attribution Non Commercial (CC BY-NC 4.0) license, which permits others to distribute, remix, adapt, build upon this work non-commercially, and license their derivative works on different terms, provided the original work is properly cited and the use is non-commercial. See: http://creativecommons.org/ licenses/by-nc/4.0/

(C) Article author(s) (or their employer(s) unless otherwise stated in the text of the article) 2017. All rights reserved. No commercial use is permitted unless otherwise expressly granted.

\section{REFERENCES}

1. Murphy BR, Prince GA, Collins PL, et al. Current approaches to the development of vaccines effective against parainfluenza and respiratory syncytial viruses. Virus Res 1988;11:1-15.

2. Collins PL, Graham BS. Viral and host factors in human respiratory syncytial virus pathogenesis. J Virol 2008;82:2040-55.

3. Nair H, Nokes DJ, Gessner BD, et al. Global burden of acute lower respiratory infections due to respiratory syncytial virus in young children: a systematic review and meta-analysis. Lancet 2010;375:1545-55

4. Borchers AT, Chang C, Gershwin ME, et al. Respiratory syncytial virus-a comprehensive review. Clin Rev Allergy Immunol 2013;45:331-79.

5. Blanken MO, Rovers MM, Molenaar JM, et al. Respiratory syncytial virus and recurrent wheeze in healthy preterm infants. $N$ Engl J Med 2013;368:1791-9.

6. Wu P, Dupont WD, Griffin MR, et al. Evidence of a causal role of winter virus infection during infancy in early childhood asthma. Am J Respir Crit Care Med 2008;178:1123-9.

7. Graham BS. Vaccines against respiratory syncytial virus: the time has finally come. Vaccine 2016;34:3535-41.

8. Polack FP. The changing landscape of respiratory syncytial virus. Vaccine 2015;33:6473-8.

9. Centers for Disease Control and Prevention. Secondary respiratory syncytial virus infection (RSV). 2016 http://www.cdc.gov/rsv/about/ index.html.

10. Welliver $\mathrm{RC}$, Checchia PA, Bauman $\mathrm{JH}$, et al. Fatality rates in published reports of RSV hospitalizations among high-risk and otherwise healthy children. Curr Med Res Opin 2010;26:2175-81.

11. Hall CB, Weinberg GA, Iwane MK, et al. The burden of respiratory syncytial virus infection in young children. $N$ Engl $J$ Med 2009;360:588-98.

12. Selwyn BJ. The epidemiology of acute respiratory tract infection in young children: comparison of findings from several developing countries. Coordinated Data Group of BOSTID Researchers. Rev Infect Dis 1990;12(Suppl 8):S870-88.

13. Weber MW, Mulholland EK, Greenwood BM. Respiratory syncytial virus infection in tropical and developing countries. Trop Med Int Health 1998;3:268-80.

14. Walsh EE, McConnochie KM, Long CE, et al. Severity of respiratory syncytial virus infection is related to virus strain. $J$ Infect Dis 1997;175:814-20.

15. Peret TC, Hall CB, Schnabel KC, et al. Circulation patterns of genetically distinct group $A$ and $B$ strains of human respiratory syncytial virus in a community. J Gen Virol 1998;79:2221-9.

16. Auksornkitti V, Kamprasert N, Thongkomplew S, et al. Molecular characterization of human respiratory syncytial virus, 2010-2011: identification of genotype ON1 and a new subgroup B genotype in Thailand. Arch Virol 2014;159:499-507.

17. Gastner MT, Newman ME. From the Cover: diffusion-based method for producing density-equalizing maps. Proc Natl Acad Sci USA 2004;101:7499-504.

18. Scutaru C, Quarcoo D, Sakr M, et al. Density-equalizing mapping and scientometric benchmarking of European allergy research. $J$ Occup Med Toxicol 2010;5:2.

19. Groneberg-Kloft B, Quarcoo D, Scutaru C. Quality and quantity indices in science: use of visualization tools. EMBO Rep 2009;10:800-3.

20. Gerber A, Klingelhoefer D, Groneberg D, et al. Antineutrophil cytoplasmic antibody-associated vasculitides: a scientometric 
approach visualizing worldwide research activity. Int $\mathrm{J}$ Rheum Dis 2014:17:796-804.

21. Hirsch JE. An index to quantify an individual's scientific research output. Proc Natl Acad Sci USA 2005;102:16569-72.

22. Hirsch JE. Does the $\mathrm{H}$ index have predictive power? Proc Natl Acad Sci USA 2007;104:19193-8.

23. Namepedia. Secondary namepedia. 2016 http://www.namepedia. org/.

24. World Economic Outlook Database. Secondary World Economic Outlook Database. 2013;2013 http://www.imf.org/external/pubs/ft/ weo/2013/02/weodata/weorept.aspx?pr. $x=75 \&$ pr.y $=10 \&$ sy $=2012 \&$ ey $=2012 \& \mathrm{scsm}=1 \& \mathrm{ssd}=1$ \&sort $=$ country $\& \mathrm{ds}=. \& \mathrm{br}=1 \& \mathrm{c}=193 \%$ 2C223\%2C924\%2C132\%2C134\%2C146\%2C136\%2C158\% $2 \mathrm{C} 112 \% 2 \mathrm{C} 111 \& \mathrm{~s}=\mathrm{NGDPD} \& \mathrm{grp}=0 \mathrm{a}=$.

25. World Bank. Secondary country and lending groups. $2015 \mathrm{http}: / /$ data.worldbank.org/about/country-and-lending-groups.

26. OECD. Secondary main science and technology indicators. 2013 http://www.oecd.org/sti/2013 1 documentation e.pdf.

27. Bächi T, Howe $\mathrm{C}$. Morphogenesis and ultrastructure of respiratory syncytial virus. J Virol 1973;12:1173-80.

28. Chanock R, ROIZMAN B, Myers R. Recovery from infants with respiratory illness of a virus related to chimpanzee coryza agent (CCA). I. isolation, properties and characterization. Am J Hyg 1957;66:281-90.

29. Blount RE, Morris JA, Savage RE. Recovery of cytopathogenic agent from chimpanzees with coryza. Proc Soc Exp Biol Med 1956;92:544-9.

30. Fricke R, Uibel S, Klingelhoefer $\mathrm{D}$, et al. Influenza: a scientometric and density-equalizing analysis. BMC Infect Dis 2013;13:454.

31. Zheng HC, Yan L, Cui L, et al. Mapping the history and current situation of research on John Cunningham virus - a bibliometric analysis. BMC Infect Dis 2009;9:28

32. Simoes EA. Respiratory syncytial virus infection. Lancet 1999:354:847-52

33. Collins PL, Hill MG, Camargo E, et al. Production of infectious human respiratory syncytial virus from cloned cDNA confirms an essential role for the transcription elongation factor from the 5 ' proximal open reading frame of the M2 mRNA in gene expression and provides a capability for vaccine development. Proc Natl Acad Sci USA 1995;92:11563-7.

34. Cranage MP, Gardner PS. Systemic cell-mediated and antibody responses in infants with respiratory syncytial virus infections. J Med Virol 1980;5:161-70.

35. Fulginiti VA, Eller JJ, Sieber OF, et al. Respiratory virus immunization. I. A field trial of two inactivated respiratory virus vaccines; an aqueous trivalent parainfluenza virus vaccine and an alumprecipitated respiratory syncytial virus vaccine. Am J Epidemiol 1969;89:435-48.

36. Kim HW, Canchola JG, Brandt CD, et al. Respiratory syncytial virus disease in infants despite prior administration of antigenic inactivated vaccine. Am J Epidemiol 1969;89:422-34.

37. Glezen WP, Taber LH, Frank AL, et al. Risk of primary infection and reinfection with respiratory syncytial virus. Am J Dis Child 1986;140:543-6.

38. Thompson WW, Shay DK, Weintraub E, et al. Mortality associated with influenza and respiratory syncytial virus in the United States. JAMA 2003;289:179-86.

39. Kurt-Jones EA, Popova L, Kwinn L, et al. Pattern recognition receptors TLR4 and CD14 mediate response to respiratory syncytial virus. Nat Immunol 2000;1:398-401.

40. Testa J. The Thomson Scientific journal selection process. Int Microbiol 2006;9:135-8.

41. Groneberg-Kloft B, Scutaru C, Kreiter C, et al. Institutional operating figures in basic and applied sciences: scientometric analysis of quantitative output benchmarking. Health Res Policy Syst 2008;6:6:6.

42. Viergever RF, Hendriks TC. The 10 largest public and philanthropic funders of health research in the world: what they fund and how they distribute their funds. Health Res Policy Syst 2016;14:12.

43. Schmidt S, Bundschuh M, Scutaru C, et al. Hepatitis B: global scientific development from a critical point of view. J Viral Hepat 2014;21.

44. Fassoulaki A, Paraskeva A, Papilas K, et al. Self-citations in six anaesthesia journals and their significance in determining the impact factor. Br J Anaesth 2000;84:266-9.
45. Merton RK. The Matthew effect in science: the reward and communication systems of science are considered. Science 1968;159:56-63.

46. Head MG, Fitchett JR, Cooke MK, et al. Differences in research funding for women scientists: a systematic comparison of UK investments in global infectious disease research during 1997-2010. BMJ Open 2013;3:e003362.

47. Köster C, Klingelhöfer D, Groneberg DA, et al. Rotavirus - Global research density equalizing mapping and gender analysis. Vaccine 2016;34:90-100.

48. Konrad-Adenauer-Stiftung. Secondary frauen in Brasilien. 2014 http://www.kas.de/wf/doc/kas_17800-1522-1-30.pdf? 091024002708

49. Huyer S, Hafkin N. Scorecard on gender equality in the knowledge society. secondary scorecard on gender equality in the knowledge society. $2014 \mathrm{http}: / / \mathrm{www}$.elsevier.com/connect/brazilian-womenlead-in-science-technology-and-innovation-study-shows.

50. Bandim Health Project. About BHP. Secondary about BHP. http:// www.bandim.org/about-bhp.aspx.

51. Council. MR. Medical research council: the Gambia unit. The Gambia Unit: Secondary Medical Research Council. http://www.mrc.gm/ourresearch/themes.

52. Adegbola RA, Falade AG, Sam BE, et al. The etiology of pneumonia in malnourished and well-nourished Gambian children. Pediatr Infect Dis J 1994;13:975-82.

53. Suara RO, Piedra PA, Glezen WP, et al. Prevalence of neutralizing antibody to respiratory syncytial virus in sera from mothers and newborns residing in the Gambia and in the United States. Clin Diagn Lab Immunol 1996;3:477-9.

54. Weber MW, Dackour R, Usen S, et al. The clinical spectrum of respiratory syncytial virus disease in the Gambia. Pediatr Infect Dis $J$ 1998;17:224-30.

55. Weber MW, Milligan P, Hilton S, et al. Risk factors for severe respiratory syncytial virus infection leading to hospital admission in children in the western region of the Gambia. Int J Epidemiol 1999;28:157-62.

56. Weber MW, Milligan P, Sanneh M, et al. An epidemiological study of RSV infection in the Gambia. Bull World Health Organ 2002;80:562-8

57. Weber MW, Milligan P, Giadom B, et al. Respiratory illness after severe respiratory syncytial virus disease in infancy in the Gambia. $J$ Pediatr 1999;135:683-8.

58. Loscertales MP, Roca A, Ventura PJ, et al. Epidemiology and clinical presentation of respiratory syncytial virus infection in a rural area of southern Mozambique. Pediatr Infect Dis J 2002;21:148-55.

59. Salomão Junior JB, Gardinassi LG, Simas PV, et al. Human respiratory syncytial virus in children hospitalized for acute lower respiratory infection. J Pediatr 2011;87:219.

60. Piñeros JG, Baquero $\mathrm{H}$, Bastidas J, et al. Respiratory syncytial virus infection as a cause of hospitalization in population under 1 year in Colombia. J Pediatr 2013;89:544-8.

61. Bardach A, Rey-Ares L, Cafferata ML, et al. Systematic review and meta-analysis of respiratory syncytial virus infection epidemiology in Latin America. Rev Med Virol 2014;24:76-89.

62. Avendaño LF, Palomino MA, Larrañaga C. Surveillance for respiratory syncytial virus in infants hospitalized for acute lower respiratory infection in Chile (1989 to 2000). J Clin Microbiol 2003;41:4879-82.

63. KEMRI Wellcome Trust Research Programm. Secondary KEMRI Wellcome Trust Research Programm. http://www.kemri-wellcome. org.

64. Fitchett JR, Head MG, Atun R. Infectious disease research investments follow colonial ties: questionable ethics. Int Health 2014;6:74-6.

65. Haynes AK, Manangan AP, Iwane MK, et al. Respiratory syncytial virus circulation in seven countries with global disease detection Regional Centers. J Infect Dis 2013;208(Suppl 3):S246-54.

66. PLOS. Secondary publication fees. http://www.plos.org/ publications/publication-fees.

67. Bio Med Central. Can charges be waived if the author cannot pay? Secondary can charges be waived if the author cannot pay? http:// www.biomedcentral.com/about/apcfaq/waivers.

68. BMJOpen. Secondary instructions for authors. http://bmjopen.bmj. com/site/about/guidelines.xhtml.

69. Akinremi TO. Research collaboration with low resource countries: overcoming the challenges. Infect Agent Cancer 2011;6(Suppl 2)S3. 